\title{
Understanding The Petty Demon Through the Perspective of Disability and Gender Theory
}

\section{Joshua Vinson}

Fyodor Sologub's tale of crazed sinfulness, The Petty Demon, has remained in the heart of Russian culture since its introduction in 1907, leaving what can best be described as an appreciated scar. The greatest Byronic tales utilize the acceptance of decadence to create complex characters that allow audiences to peer into the darker side of humanity, and often themselves, while still maintaining some emotional connection to the antihero. While the depravity displayed in The Petty Demon is often the most prominent feature, the contrasted relationships of the characters Lyudmila and Peredonov reveal key insights toward understanding of the novel's thematic and socioemotional framing of women and the mentally ill. These patterns are analyzed in the context of the novel and compared to those in other works of the Russian canon with the help of papers by Hustis, Mills, and Greene. Lyudmilla's few unsatisfactory and foreign excuses for her perversion fail to help her escape the sexist symbolism she embodies as a female character, resulting in her solidification as a gossiping temptress with little room for reader empathy or a separation from the basic stereotypes women were already saddled with. Peredonov's escalating madness is contrasted against her evils in a manner that accentuates her follies while failing to separate many of his cruel actions from his mental illness. The resulting feelings coalesce to project the characters' worst qualities upon the innocent and underprivileged through the vehicles of familiar archetypes, contributing to the perpetuation of harmful cultural perspectives on such groups.

\section{| Introduction}

Sin is in. Once again, as during the anti-establishment, anti-realist, decadent era of the late 19th century, antiheroes are popular! Their evils are interesting and exciting, their backstories and flaws effectively pitiful and sympathetic, and their inevitable karmic punishments morally satisfying. Decadent audiences, both in the 19th century and today, enjoy the antiheroes 
of The Petty Demon for each of these reasons, but the best Byronic tales are never simply decadent for decadence's sake; they use pain, pity, and punishment to spin together themes and characters of greater depth while the slightly opened moral vault of society still allows normally shamed traits and plot ideas to be enjoyed. This temporary release is what gave rise to the despicable acts of Peredonov and Lyudmila, the novel's thematic pair. While the unbridled decadence of Fyodor Sologub's The Petty Demon (1907) is often the main focus of readers and critics, the contrasted relationships of Lyudmila and Peredonov reveal deeper, more impactful truths about the nature of the novel's framing and its relevance to the societal view of women and the mentally ill. Studies by Judith Mill, Harriet Hustis, and Diane Greene demonstrate the thematic shifts between characters in the realms of decadence, symbolism, and disability and gender theory.

Every piece of the thematic web in The Petty Demon is strongly tied to Peredonovthe unbelievably pathetic, undeniably detestable, and unreasonably stupid teacher who quite easily causes the most suffering throughout the novel. Each of his actions appear to be made either entirely without regard for others or with the intent of causing misery, though much of his behavior simply causes more trouble for himself. We quickly begin to grasp his outlook and social standing from his introduction on the first page: "Peredonov, a teacher at the gymnasium, stood in a circle of his friends, gazing sullenly at them with small swollen eyes from behind gold framed spectacles." His figure is full of solemn irony, similar to the image presented in the preceding line: the pretty town was not actually full of amiability; rather, "it only seemed that way" (Sologub 1). His friends are hardly amiable, and the town is surprisingly unwelcoming.

Peredonov's fellows are cheery as he stands by miserably, not just bored but also clearly antagonistic towards these "friends." The conversation contains nothing that signifies a sense of abnormality, and this sour disposition continues as we read. It is displayed early on that his normal state of being, even when in the company of friends of the same hierarchical status, is one of contempt. Peredonov's close friend Rutilov chooses to shame him for believing Varya rather than suggesting caution or offering advice in private. Peredonov continuously widens the chasm between himself and the group, even flashing his "rotten-looking teeth" in an ugly grin as he seethes with anger.

Peredonov and his wife-to-be, Varya, treat each other despicably. Emotional abuse rages as Varya hatches a plan to deceive Peredonov into marriage while Peredonov threatens to marry other women, and actively courts them, all while both hurl devastating insults at each other. In our first introduction to Varya, Peredonov speaks of their friend Marta, teasing, "But she's prettier than you, ... maybe I'll go ahead and marry her." Enraged, Varya becomes "red and trembling with malice" and threatens to harm Marta. The argument continues loudly until Peredonov spits in Varya's face (Sologub 45). With no respect given by either partner, Peredonov's home life is miserable: the two wretched souls compound their suffering together. He makes no allowance for charity in any area of life. These early examples can be extrapolated to his treatment of his students, like the persecuted, androgynous schoolboy Sasha, and to any others he thinks of as below himself.

Throughout the novel, we can see Peredonov's worsening mental state exacerbate his natural cruelty, and his thoughts and actions become increasingly erratic. Peredonov begins to see a creature referred to as a nedotykomka. It is never defined within the novel as real or imaginary, but the name is understood in Russian as referencing a type of mischievous spirit. 
Peredonov, due to his own increasing madness or to the actual existence of the nedotykomka, begins to physically lash out against perceived threats in ways uncharacteristic of the simple dullard we find at the start of the novel. Sure, Peredonov is a constant victim of gossip, largely disliked by his peers, and his suspicions about Varya tricking him into marriage are founded; however, no one is secretly trying to harm him, nor does it seem that had ever been the case. He consistently fears that others are lying to or about him, even acting fake to his face in order to kill him. This theme has been subtly displayed since the very first scene when Volodin remarked that "it's possible to say anything" (Sologub 1). Hustis writes that the concept of hidden truth couples with Peredonov's existing paranoia and the introduction of the nedotykomka, since he had always suspected magical interference, as with the "counterspell" he must cast to avoid Volodin's spell, or the charms he believes can lure him into others' homes. But now that something is actually materializing for him, he is presented with a much greater reason to fear deception. Peredonov's personal counter-spells soon stop working on the nedotykomka leaving him helpless and without knowledge of this antagonizing force. Is this an actual demon or spirit? Is it in his head? Is it the work of an enemy? No matter the answer, he believes he has good reason to worry, and this stress helps to push him over the brink, resulting in his escalating insanity and in the eventual murder of Rutilov.

While Peredonov's arc focuses mainly on his increasing madness, Lyudmilla displays an increasing willingness to give into her decadent inclinations. She is usually considered to be one half of the pair that stands in opposition to Peredonov because of her relationship with Sasha, their two storylines coinciding in escalation as the story progresses. However, there deserves to be a different set of pairings with these two aligned separately: Lyudmilla and Peredonov by the framing of their actions, and Sasha and Peredonov by their connection to reality. The symbolist and decadent nature of Sologub's work uses elements of the spiritual, mystical, and taboo to stretch beyond the normal bounds of the preceding naturalist writing to display this powerful web of connections (Rosenthal and Foley).

Lyudmilla stands in opposition to Peredonov not only as a woman but also in her ability to draw sympathy from others and in her mastery over language. She makes herself and her wishes known quite easily and is formally introduced during Rutilov's attempt to get Peredonov to marry one of his sisters. Lyudmilla is the oldest of the three and a master of gossip; in fact, when the sisters are made to tell Peredonov how they would please him as his wife, gossip is the boon she offers. Mills writes that Lyudmilla is held above others in this regard, being one of the few characters with the ability not only to ignore gossip, but to control it (Mills 6). On one hand, while Peredonov does circulate gossip, as with his manufacturing of Gudaevskij's socialism and his spreading of Sasha's supposed womanhood, he is undoubtedly a victim of it; he is described by Mills as a "corpse motivated by external forces that toy with him and then toss him aside" (Mills 18). Besides the obvious frustration, alienation, and paranoia that it causes him, it is the gossip of his friends, which he misunderstands entirely, that leads him to kill Volodin. In stark contrast to Peredonov's vulnerability to gossip, Lyudmilla operates freely and innocently in the public eye by framing others and keeping her image clean. When she and Sasha are caught and accused of their acts of transvestitism, Lyudmilla easily brushes the ordeal aside and continues to amplify her reputation of purity and control to protect Sasha's and her societal standing. She frames a crossdressing situation early on as a play and later portrays herself and her sisters as "cheerful girls with sharp tongues," simultaneously 
displaying the reason that "the other geese around here have no liking for [them]" (Sologub $233,253)$. Mills describes her actions well in relation to her influence on Sasha:

Lyudmila's values are alternative ones even in the society portrayed. She initiates Sasha into her own brand of physical pleasure tinged with sadism and homosexuality in a relationship which would cause an uproar if the town were to discover it. Yet, Lyudmilla has her own way. The gossip that springs up around her does not interfere with her actions, and at the end of the novel she is free to continue her activity unhampered. (Mills 6)

Lyudmilla's mental state is also displayed in reverse to Peredonov's. While she is just as perverse and socially powerful at the end of the novel as at the beginning, her decadence and moral blight, or at least our perception of these, increase proportionately to Peredonov's. On one side, he reaches out because of his paranoia and stress, demonstrating a greater tendency to harm others and give in to superstitions and gossip. Meanwhile, Lyudmilla ramps up from tempting and teasing Sasha to seducing him, eventually corrupting him with her decadent schemes. Their situation is so questionable by the end of the novel that the consummation of the relationship, while never directly mentioned, is entirely possible or near in the future (Ehre). The difference between these two antiheroes is Peredonov's deteriorating mental condition-the man falls deeper into evil while the woman appears to simply delve into it. The distinction on gender made here is the crux of others' arguments as well as my own about Peredonov and Lyudmilla and the language used to represent them.

Gender is weaponized in The Petty Demon, and it is a division to which weaponized archetypes can be applied. In art, sympathy is granted more often to the gender in power, the gender of the writer, the gender of the intended audience, or to the gender more valued in the relevant artistic era (Greene). Men easily fill the first three of these categories when speaking of this novel, and Lyudmilla suffers even greater under this bias because of her talent with gossip. While this is her "gift" to Peredonov, gossip is often used to demonize women in literature. "The speech of idle women," as it is recognized by feminist critic Kristen Pond, is a framing of natural conversations by women as inherently devious or malicious, used by men to project both ill intent and lack of effort on women deemed to be frivolous or mischievous. Lyudmilla is not only as naturally dark and decadent as Peredonov, but she is also dangerous instead of dull, using her time to stir trouble in the manner stereotypical of demonized women. Her comparative lack of ability to garner sympathy has less to do with her actual deeds than the context in which they lie. Her full understanding of and glee with the situation amplifies her perceived guilt while Peredonov's increasing madness continuously detracts from his own. On all other stations they can be considered equals in evil, though the worst acts Peredonov commits before truly diving into insanity are his assisting the whipping of an innocent boy and cuckolding of the boy's father. However, the gender/ pity gap stretches beyond these early contrasts, as elements of Symbolist art begin to bleed into the mix. Symbolists, as portrayed in some of their more famous art pieces and character obsessions, had a strong tendency to focus on the vices of their human muses. Whether they were being led into sin or perpetuating evil themselves, women in particular were models for the display of distasteful aesthetics: strong lust and lasciviousness, insatiable envy, and, as is prominent in Lyudmilla, the particular aesthetics of whom cross over even more into 
decadent art, a desire to escape the boundaries of society and common morals. This last archetypal feature is likely due to the growing emphasis on unrestricted emotion during the Symbolist/Decadent era, a trend that led to representations that displayed a lack of control over or significant remorse for actions when the motivations were emotionally "pure" or sincere from the figure's perspective, allowing sexual habits of unnatural or immoral varieties to be portrayed. Lyudmilla's essential nature was positioned opposite Peredonov's as one completely undeserving of mercy because of the application of such characteristics.

Although Lyudmilla does not fit into some of the more famous roles for the discarding and disparagement of otherwise neutral female villains, like the "madwoman in the attic," she does display excessive perversion and a fondness for gossip and scheming, traits popular among symbolists and decadents for portraying the immorality of women. However, these characteristics are more specifically demonized in non-decadent eras because of the increased celebration, or simple acceptance, of normally immoral behaviors. Nevertheless, the elements of sexual temptation, amorality, and abject evil involved in famous symbolistic characters like Pornocrates [Figure 1] and Salome [Figure 2] are structures that enhance negative bias against them rather than create sympathy, these being the same tools used to construct Lyudmilla. She offers some thought about what led her to the point of her perverse state of living; but the short ponderings on her past do not grant any foundation for sympathy. The same cannot be said about Peredonov.

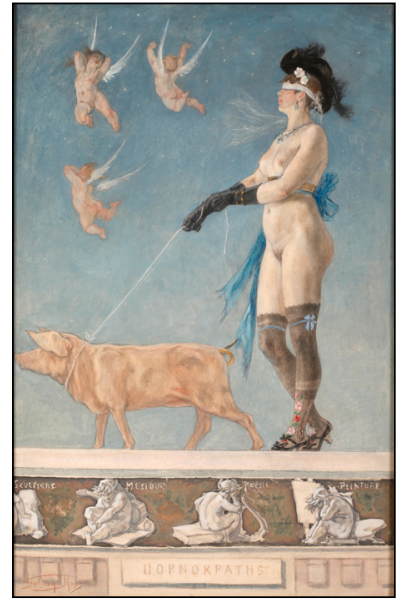

Figure 1:

Rops, Félicien.

Pornocrates. 1878,

Musée provincial Félicien Rops, Namur

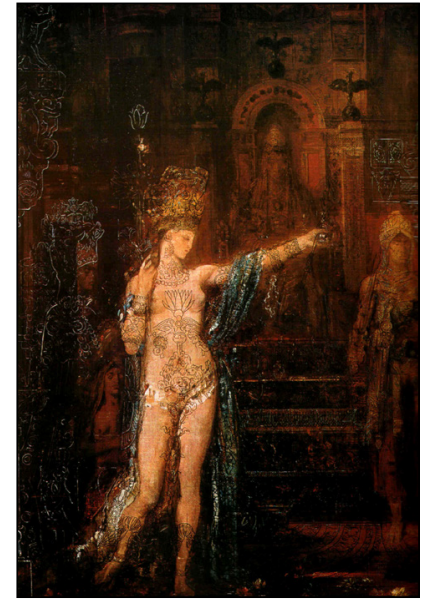

Figure 2:

Gustave Moreau,

Salomé dansant devant Hérode. 1876, Musée Gustave-Moreau, Paris

The main trait given to Peredonov, besides his decadent ill-intent, is suffering. Whether it spawns from his stupidity, paranoia, or poor relationships, readers are continuously given reason to pity our male antihero. The demon manifests itself for him and no other, driving him to do things out of his natural character; indeed, his greatest crimes could be considered entirely the result of "outside forces." Hustis reminds us that if it were a demon messing with his mind, he would be largely innocent. More likely, though, had he become clinically insane, we would consider him even less guilty, at least in a court of law. He does not start the fire simply out of spite or malice, but rather because "the fiery nedotykomka, leaping about the 
chandeliers, laughed and relentlessly tried to inspire Peredonov with the idea that he ought to light a match and set this fiery, but captive nedotykomka loose," and "after having had its fill," it might then "leave Peredonov in peace" (Sologub 251). In the very end he is as good as mentally gone, the agony and madness described in a frighteningly vivid manner on the penultimate page:

By now everything seemed like a delirium to him, senseless, disconnected, and surprising. He had a torturous headache. One notion kept repeating itself with persistence-the one about Volodin as an enemy. It alternated with oppressive fits in which he was assailed by the insistent idea that he had to kill Pavlushka before it was too late. (Sologub 258)

The purpose in contrasting Peredonov and Lyudmilla, one sick and the other a devil, is not necessarily to argue for the morality of either's actions but rather to analyze the methods used to frame particular groups against others with little recognition of their status in society. The woman here is positioned against the man as a pure incarnation of conniving mischief and sexual immorality of the worst nature. Within the context of the novel, or at least in the deeper critical contrast against Lyudmilla, Peredonov's innocence by mental illness can be seen as somewhat valid, but in the larger context of the novel's popular application to society, this factor is forgotten.

No matter the pity or excuses one gives him, it is certainly difficult to like Peredonov as a character-it should tell you something when a name takes on greater form, as "Peredonovism" has come to describe people that embody "greediness, egotism, pettiness, and lechery" (TIME 80). Sologub points the sights of Peredonovism toward his audience in the second edition, somewhat angering the Russian people, while scholar Andrew Field takes the theme and applies it to Sologub's other works. Field writes specifically on its influence as a thematic layer in The Created Legend in the character Prince Tankred, the haughty, superficial, and dark imitator. My paper brings the topic of the perception of evil to the surface in order to recognize that nearly every instance I have found of the study of Peredonov and Peredonovism leaves out any substantial consideration of schizophrenia. Forgoing this consideration in an academic paper would ignore the thematic changes and implications that come with the recognition of a character's disability.

The madness that Peredonov experiences can be interpreted in a variety of ways, but as Harry Snyder writes in "The Gogolian Echoes in Sologub's 'The Petty Demon': Are They Imitative of or Organic to Gogol's 'Dead Souls'?" his symptoms are similar to those of schizophrenia, a mental illness that can cause "disruptions in thought processes, perceptions, emotional responsiveness, and social interactions," and may include "psychotic symptoms such as hallucinations, delusions, and thought disorder (unusual ways of thinking), as well as reduced expression of emotions, reduced motivation to accomplish goals, difficulty in social relationships, motor impairment, and cognitive impairment" (NIMH par. 1-2). The condition also manifests in three stages: "prodromal (or beginning), acute (or active), and recovery (or residual)" (AIPC par. 4-8). This disability theory reading of the novel allows for a rather simplified interpretation of the narrative in which Peredonov moves from the more passive prodromal stage into the acute as his visions, or hallucinations, worsen and he experiences the psychotic break. 
While we cannot be absolutely certain that Peredonov had schizophrenia, as the term originated in 1908 six years after the serial publishing, the lens of mental illness can help us understand his overall condition. Peredonov's paranoia, social dysfunction, depressive state, and poor executive function worsen throughout the novel, lending to the interpretation of his actions as a result of either suffering or a potential mental illness rather than mere supernatural intervention. Specifically, Milton Ehre writes that "above all he is emotionally dead" (Ehre). Ehre notes Sologub's use of "black melancholy" for humor and the descriptions of Peredonov as "'gloomy,' 'dull,' 'despondent,' 'indifferent,' 'dreary,' and 'lonely.'" The point is finally driven home with the narrator's description of Peredonov's walk through the "bleak" weather, "depressing silence," on an "impotent and unclean earth," "alienated from the heavens." All the while he walks "wearied by vague fears," and, "as always he looked at the earth with dead eyes, like a demon, tormented in his dreary solitude by terror and anguish" (Sologub 208).

Snyder's analytical comparison of the thematic echoes of Gogol's Dead Souls in The Petty Demon also likens Peredonov's insanity to paranoid schizophrenia specifically. Snyder uses examples of his "permanently lodged" fears of gossip and unreasonable, obsessive, and superstitious actions around the nedotykomka, when suspecting spells from others, and when dealing with the three-cornered cap to display a contrast to Gogol's grotesque, dehumanized caricatures (Snyder 3). However, Peredonov and his traits are not successfully separated or understood in the eye of culture and overall literature critique-his story lives on as a tool for dehumanization without any regard for the more complex factors that influenced Peredonov and, more importantly, those that could be influencing individuals made out to be "Peredonovs" themselves. Whether or not his condition can be absolutely determined, he can be likened to those displaying similar traits.

As mentioned, "greediness, egotism, pettiness, and lechery" are the main qualities used to define the popular application of Peredonovism, but his escalating madness is the central focus of the novel (Snyder 4). Hence, the ever-increasing display of symptoms and eventual psychotic break are tied indefinitely to his character and to society's use of Peredonovism. Thus, the basic existence of Peredonovism as a means to frame people with a caricature that appears to fit the situations produces two negative effects in consideration of our modern understanding of disability theory and social psychology. First, because of the gradual synchronization of Peredonov's symptoms with his decadence and pettiness, those that suffer from similar symptoms or mental illnesses are at risk of being unnecessarily grouped into or compared to a category of effectively rotten people. Additionally, the social factors, past experiences, and mental conditions that can cause such personal traits to be observed may be ignored in favor of the easier option of aligning the person with a familiar construct (Mulvaney). Hustis agrees that while Peredonov is foul-even well before his psychotic breakand that neither his mental illness nor overall suffering can fully account for his wicked tendencies, the character is shrouded in such ambiguity within the novel that society has an easier time recklessly applying his negative traits to those that do not deserve them but are similar on other levels (Hustis). Surely, the theoretical moral conflict and literary disability analyses act to thoroughly deepen his character, but they should not be considered of equal value to the disadvantages that these characterizations cause for those that suffer when the greater part of readers do not consider such nuances. It is exactly these circumstances which have formed the new social model of disability. In contrast to "impairment," which is the 
physical or mental effect itself, "disability" is defined by famous theorist Michael Oliver as "the disadvantage or restriction of activity caused by a contemporary social organization that takes no or little account of people who have impairments," leading to exclusion from social activities. Sadly, Peredonov is only one man in a long lineage of characters that cast a poor light on the mentally ill community, with misrepresentations and overly vague distinctions between illness and immorality still being introduced in our entertainment today.

Do I believe there was ill intent behind Sologub's creation of Peredonov? This is more difficult to say, and the literature on The Petty Demon offers little help, but his own words on the inspiration for the characters and events in the novel highlight both a desire to portray real events from his time in provincial Russia and to frame certain persons or groups as "Peredonovs," leaving the evidence nearly split (The Petty Demon 2nd Edition). Additionally, it is more difficult to lay blame on writers of this age because of the lack of development of disability theory at the time; rather, the importance now is to analyze the effects and implications of these past works in order to create a more positive portrayal of the mental health community.

Decadence is predicated on the idea of decline. As the movement gradually developed, the once degrading labels of decay and vulgarity originally ascribed to it became part of the ethos of Decadent artists. Corruption, a form of this decline, is a prominent theme in many of Sologub's works. Most often, he utilizes corruption as a mechanism to display a loss of innocence in children, whether it occurred before the story, during its course because of an "evil" adult, or simply as a result of unfortunate circumstances. Children are often considered to be naturally pure, so they are good models for displaying a sense of Decadent loss: Sasha, for example, is the lost child of The Petty Demon, his corruption occasioned by Lyudmilla. This role casts her as a source of corruption rather than as a clear victim. Peredonov, while not losing any innocence, displays a more general sense of corruption, inwardly more so than outwardly, as his mental state hastily deteriorates. Peredonov and Lyudmilla occupy opposite ends of the spectrum, even in the realm where moral decay and distastefulness are celebrated. Audiences' respect for the Decadent Period's unbridled portrayals of vulgarity allowed these characters' perversions, egos, and cruel personalities to take center stage in a time of social boredom and angst; this has resulted in two despicable personalities whose present legacies continue to influence the perception of certain social groups, despite their separation as victimizer and victimized.

Peredonov and Lyudmilla's decadent actions earned them fame and thematic partnership in the late 19th century, but their location within the larger context of The Petty Demon and usefulness to society as figures of literary interest bring along a great deal of baggage in the 21 st century. Lyudmilla's deterministic and paganistic excuses for her seduction of the young Sasha do little to help her escape the sexist symbolism she embodies as a female character, leaving her as a foul, mischievous temptress to the detriment of women attempting to escape these stereotypes. Peredonov's projection against her works in the inverse manner, with his potential excuses, general suffering, and mental illness, together coalescing to impose his worst qualities upon the innocent and already disadvantaged. Gender and Disability Theory can and will continue to be used to highlight the flaws and foibles of such characters so that complex, interesting, and varied narratives can be written long into the future, aiding the members of our society that are still fighting for equality and acceptance. 


\section{References}

Ehre, M. "Fedor Sologub's The Petty Demon: Eroticism, Decadence and Time." The Silver Age in Russian Literature, edited by John Elsworth, Palgrave Macmillan, 1992. https://link.springer. com/chapter/10.1007/978-1-349-22307-7_8. 10 Nov. 2019.

Field, Andrew. "The Created Legend: Sologub's Symbolic Universe." The Slavic and East European Journal, vol. 5, no. 4, 1961, pp. 341-349. JSTOR, www.jstor.org/stable/305123. 10 Nov. 2019.

Greene, Diana. "Insidious Intent: An Interpretation of Fedor Sologub's 'The Petty Demon."' Canadian Slavonic Papers, vol. 29, Iss. 4, 1987, 473. ProQuest. 20 Nov. 2019.

"Structure and Meaning in Sologub's 'Petty Demon." Ulbandus Review, vol. 1, no. 2, 1978, pp. 26-36. JSTOR, www.jstor.org/ stable/25748029. 12 Nov. 2019.

Hart, Pierre R. "Metaphor, Metonymy and Myth in The Petty Demon." The Slavic and East European Journal, vol. 41, no. 3, 1997, pp. 431-441. JSTOR, www.jstor.org/stable/310185. 10 Nov. 2019.

Hustis, Harriet. "Wicked Tongues and Alternative Lifestyles: Lyudmila, Peredonov and the Role of Language in Sologub's The Petty Demon." The Slavic and East European Journal, vol. 40, no. 4, 1996, pp. 632-648. JSTOR, www.jstor.org/ stable/310104. 10 Nov. 2019

"Memorable Monster." TIME Magazine, vol. 80 , no. 10, Sept. 1962, pp. M22-80. EBSCOhost, search.ebscohost.com/login.aspx?direct $=$ true \&db=a9h\&AN=54209275\&site $=e-$ host-live.

Mills, Judith M. "Expanding Critical Contexts: Sologub's Petty Demon." The Slavic and East European Journal, vol. 28, no. 1, 1984, pp. 15-31. JSTOR, www.jstor.org/stable/307084. 12 Nov. 2019
Mulvany, Julie. "Disability, Impairment or Illness? The Relevance of the Social Model of Disability to the Study of Mental Disorder." Sociology of Health \& Illness 22.5 (2000): 582-601. https:// onlinelibrary.wiley.com/doi/pdf/10.1111/14679566.00221. 15 Nov. 2019.

Oliver, Michael. "The Social Model of Disability: Thirty Years On." Disability \& Society, vol. 28, no. 7, 2013, pp. 1024-1026., doi:10.1080/0968 7599.2013.818773. 14 Nov. 2019.

"An Overview of Schizophrenia." AIPC Article Library, 16 Apr. 2013, www.aipc.net.au/articles/ an-overview-of-schizophrenial.

Pond, Kristen A. "Harriet Martineau's Epistemology of Gossip." Nineteenth-Century Literature, vol. 69 , no. 2, 2014, pp. 175-207. JSTOR, www. jstor.org/stable/10.1525/ncl.2014.69.2.175. 11 Nov. 2019.

Rosenthal, Charlotte, and Helene Foley. "Symbolic Patterning in Sologub's The Petty Demon." The Petty Demon: 324-332.

Schimmelmann, Benno G., et al. "Pre-treatment, baseline, and outcome differences between early-onset and adult-onset psychosis in an epidemiological cohort of 636 first-episode patients." Schizophrenia Research 95.1-3 (2007): 1-8. https://www.sciencedirect.com/science/article/ pii/S0920996407002587?casa token=OOzMzq6WTHAAAAAA:NE9Kwt-1f05jnNkMxUgl_ sSiAmRKgZ1YV32p7ZFWKAZ9WVvZYHQfgLAD85GFI3XXjpPdd10. 15 Nov. 2019.

"Schizophrenia." National Institute of Mental Health, U.S. Department of Health and Human Services, May 2018, www.nimh.nih.gov/health/ statistics/schizophrenia.shtml.

Snyder, Harry. "The Gogolian Echoes in Sologub's 'The Petty Demon': Are They Imitative of or Organic to Gogol's 'Dead Souls'?" Modern Language Studies, vol. 16, no. 3, 1986, pp. 189-205. JSTOR, www.jstor.org/ stable/3194899. 12 Nov. 2019.

Sologub, Fyodor. The Petty Demon. Trans. Samuel D. Cioran. Ann Arbor, MI: Ardis, 2014. 
